\title{
Pharmacodynamic analysis of an agonistic antibody to the costimulatory receptor GITR
}

\author{
Gordon Moody*, Jodi Moriguchi, Ji-Rong Sun, Patricia McElroy, Hong Tan, Yannick Bulliard, Beltran Pedro \\ From 30th Annual Meeting and Associated Programs of the Society for Immunotherapy of Cancer (SITC 2015) \\ National Harbor, MD, USA. 4-8 November 2015
}

GITR/TNFRSF18 is a member of the TNF-receptor superfamily preferentially expressed on regulatory $\mathrm{T}$ cells (Tregs) and activated $\mathrm{T}$ effector cells. Antibody agonists to GITR claim two distinct mechanisms to overcome the repressive tumor microenvironment and drive anti-tumor efficacy in vivo: receptor agonism (forward signaling) on $\mathrm{T}$ effector cells and Fc $\gamma \mathrm{R}$-mediated Treg depletion. We sought to better understand the contribution of these two mechanisms using pharmacodynamic readouts relating target coverage, Treg depletion and efficacy using isotypic variants of a surrogate antibody against mouse GITR, DTA-1.

First, target coverage was determined in spleen, tumor and draining lymph node following treatment with a single dose of mouse IgG2a DTA-1. In this study, efficacy correlated with doses that covered $>90 \%$ GITRexpressing intratumoral leukocytes and depleted $>90 \%$ intratumoral Tregs at 24 hours post-dose. Though displaying equivalent agonistic activity in vitro and achieving a similar level of target coverage, the mouse IgG1 N297A variant of DTA-1 neither depleted Tregs nor displayed anti-tumor activity in vivo, in confirmation of recent literature. To further explore the influence of Fc engagement, additional DTA-1 isotypic variants were generated and tested in vivo. In this study, we confirmed that preferential engagement of Fc $\gamma$ receptors was necessary for optimal activity, as the mouse IgG1 DTA-1 variant failed to regress tumors. Additionally, we identified a variant with enhanced Treg depletion properties, however, the enhanced depletion did not translate to improved anti-tumor efficacy.

Lastly, we sought to understand if mouse IgG2a DTA1-would enhance the effect of PD-1 / PD-L1 blockade in vivo. Using the MC38 tumor model, we observed synergistic tumor regression in the combination group

Amgen, Inc., Thousand Oaks, CA, USA and take full advantage of:

- Convenient online submission

- Thorough peer review

- No space constraints or color figure charges

- Immediate publication on acceptance

- Inclusion in PubMed, CAS, Scopus and Google Scholar

- Research which is freely available for redistribution 